\title{
Preliminary results from permanent GPS array by the Geological Survey of Japan in conjunction with groundwater-level observations
}

\author{
Ryu Ohtani, Naoji Koizumi, Norio Matsumoto, and Eikichi Tsukuda \\ Geological Survey of Japan, Agency of Industrial Science and Technology, Japan
}

(Received December 31, 1999; Revised August 7, 2000; Accepted August 7, 2000)

\begin{abstract}
A regional continuous Global Positioning System (GPS) array, consisting of uniform antenna type, has been established by the Geological Survey of Japan (GSJ) mainly around the Kansai district. Geodetic results for 2.5 years data are as follows. In comparison with the solutions obtained from the Geographical Survey Institute (GSI) continuous GPS array which employs different type of antenna from the GSJ's array, it was found that the agreements between the daily positions were about $10 \mathrm{~mm}$ in horizontal and 15 to $20 \mathrm{~mm}$ in vertical components. This result indicates that the influence of the antenna type difference is at this level. The GSJ's GPS stations around the Kansai district were found to have a common annual variation in the vertical component, whose amplitude was different from site to site. There were small correlations with in situ measurements of groundwater-level variation, except for the two stations whose annual variations of the GPS vertical component were the largest. The vertical displacements due to elastic deformation by groundwater-pressure changes in the aquifers were estimated using a simple model, but they were too small to account for the observed variations.
\end{abstract}

\section{Introduction}

The development of space geodetic techniques such as GPS and Very Long Baseline Interferometry (VLBI) enables us to monitor crustal deformation accurate to a few $\mathrm{mm}$ and a few $\mathrm{cm}$ levels for horizontal and vertical components, respectively. Recently, many continuously operating GPS (CGPS) networks had been established worldwide. Owing to their good spatial and temporal coverage in conjunction with the high precision, various kinds of crustal phenomena have been detected and studied. They include, detection of slow events associated with postseismic slip (Heki et al., 1997) and aseismic fault slip (Geographical Survey Institute, 1997), determining microplates or segment boundaries of crust (Tada, 1996), and estimating strain accumulation rate along plate boundaries (Sagiya, 1999).

However, they are being used only for studying secular (linear) trends such as plate motions, and it is still difficult to discuss non-secular station position variations except for the events with relatively large displacements. This is often due to unknown annual variations in GPS time series, which makes it difficult to identify variations associated with crustal deformation with timescales shorter than a year. One of the most possible causes for the annual variations is troposphere mismodeling in GPS analysis. Since most of mapping functions are held fixed irrespective of changes of the atmospheric conditions such as tropopause height, the mismodeling can cause seasonal variations of station position estimates, especially the vertical component due to its strong correlation with tropospheric delay parameters. Azimuthal symmetry

Copy right (C) The Society of Geomagnetism and Earth, Planetary and Space Sciences (SGEPSS); The Seismological Society of Japan; The Volcanological Society of Japan; The Geodetic Society of Japan; The Japanese Society for Planetary Sciences. assumption in mapping functions can induce errors in the estimation of station positions. Other possible causes for annual variations in the estimated GPS station positions include ocean tidal loading and atmospheric loading, which are not always modeled in GPS analysis. The errors due to reference frame may cause annual variations in the estimates. However, the causes of the annual variations have not been identified completely yet.

Recently, Matsumoto $(1996,1998)$ showed a strong correlation of the annual variation between the groundwater level at a shallow well and the height obtained from the measurement by levelling every 3 months at Hamaoka, Japan. He also calculated the ground displacement due to withdrawal and intrusion of the groundwater into the aquifer using the measurement of compaction and expansion coefficients obtained from drilling core and showed that the amplitude of the calculated height was comparable with the measurement. This result strongly suggests the groundwater effect to the annual variation of the ground motion. There is also a possibility that annual height variation observed in GPS estimates is caused by groundwater variation in some cases. However, there are few simultaneous observations of groundwater with GPS to confirm this hypothesis.

There are many other error sources mentioned above. One of them is due to phase center variation (PCV). PCV is caused by nonuniform antenna phase characteristics (Meertens $e t$ al., 1997) and/or signal scattering from structures associated with the mount of a GPS antenna (hereafter we refer to it as antenna mount; see Elósegui et al., 1995). Since individual antenna type has its own antenna phase characteristic, differences of antenna types can produce different solutions of station position estimates. Especially, when several kinds of antenna type and/or antenna mount are mixed within a sin- 


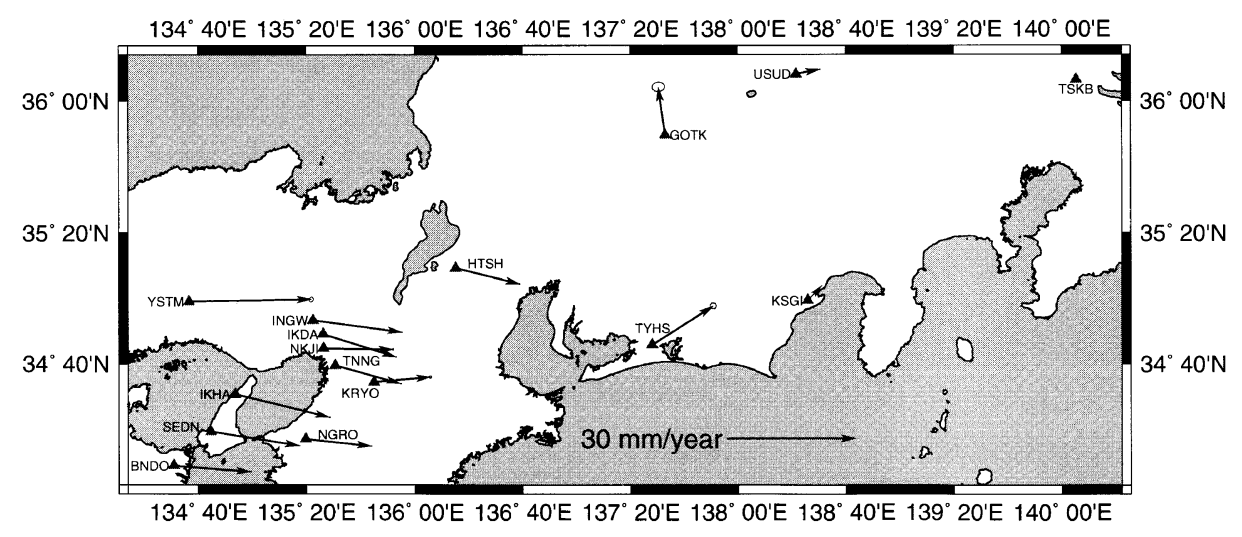

Fig. 1. Location map of the GSJ's CGPS stations and two IGS stations (TSKB, USUD). The horizontal velocities relative to TSKB derived using the data from July 1996 to December 1998 (for TYHS, GOTK, and YSTM, the observations started from 1998) are also shown.

gle network, it would cause serious errors in all of station positions' estimates (Jaldehag et al., 1996). Only a constant bias would be produced by these PCV-related errors when analysis session is set to be a sidereal day. However, since it is general in GPS analysis to process data for one day session, the errors due to PCV can acquire time-dependent characteristics.

In this paper, preliminary results on the issues mentioned above are discussed using the data from the GSJ's CGPS array. GSJ established the regional CGPS array mainly around the Kansai district in 1996 for inland earthquake prediction research after the disastrous Kobe earthquake in 1995 (Tsukuda et al., 1996). It consists of 14 GPS stations, all of which are colocated with observation wells of groundwater level. At most of the stations, observations by borehole strainmeters, seismometers, barometers, and rain gauges are routinely operated as well as GPS.

These data can be utilized to establish the theory to explain changes in groundwater level associated with earthquakes. There have been many reports of groundwater-level anomalies before and after earthquakes (Roeloffs, 1988). The most likely explanation for these groundwater-level anomalies is that pre- and/or post-crustal deformation could cause these groundwater anomalies since many theoretical studies and observations show that groundwater levels are very sensitive to crustal deformation under certain conditions, especially to crustal volumetric strain changes. To detect such changes more precisely and to understand physical process of them, GSJ developed the array of observation wells, some of which are equipped with GPS and borehole strainmeters (Koizumi et al., 1999).

Although the array was primarily deployed for the purpose of determining regional crustal deformation to relate it to changes in the groundwater level and/or the borehole strain, it can be used to study the geodetic issues mentioned above by comparing the GPS results with the in situ groundwater-level measurements and the results obtained from another CGPS array operated by GSI, which is called "GEONET." First, the geodetic solution obtained from the GSJ's array is compared with that from GEONET to investigate PCV influences on GPS analysis. Then, vertical position variations of the GPS stations are compared with groundwater-level variations to investigate their relationship.

\section{GSJ's Continuous GPS Array and Data Analysis}

The GSJ's CGPS array was established with 10 GPS stations deployed over the Kansai district (plus one station at KSGI) in 1996 in addition to 3 stations deployed in 1998 (TYHS, GOTK, and YSTM; see Fig. 1). All stations are equipped with Dorne-Margolin antennas-plus-choke ring assemblies with TurboRogue receivers. All of the antennas are equipped with a same type of antenna mount and with a same type of radome to avoid problems arising from mixing different types of antenna and radome. All of the antennas deployed over the Kansai district (except for the Nakoji station (NKJI)) and at the Ohtaki station (GOTK) are put on 2- to 5-m-high pillars and the others are directly attached on the roofs of the observation huts. They are located on sedimentary basins and none of the GPS pillars are built on bedrock.

24 hour observation data are recorded with the sampling rate of 30 seconds and with a 15-degree elevation cutoff. They are automatically sent to GSJ at Tsukuba and processed to estimate daily positions using the GPS Inferred Positioning System (GIPSY) analysis software (Webb and Zumberge, 1993, and references therein). In the routine analysis, additional GPS data from two International GPS Service (IGS) stations, Tsukuba (TSKB) and Usuda (USUD), equipped with the same type of antennas with TurboRogue receivers, are included in order to compare the station position estimates with the result of routine analysis of GEONET by GSI that often displays station position velocities relative to a station near TSKB. Information on precise GPS satellites orbit, their clocks error, and the data of Earth rotation parameters are procured from the Jet Propulsion Laboratory (JPL) (Zumberge et al., 1995) and fixed. Fiducial orbit and consistent Earth rotation parameters are used to realize a corresponding ITRF coordinate. Ionospheric-free linear combination of phase data are formed to remove the ionospheric delay. Then, daily station positions, zenith total delay, receiver clocks error, and integer phase ambiguities are estimated using the Lanyi mapping function with the default constant meteorological condition parameters (Lanyi, 1984). In the modeling of the GPS station position, variations due to ocean tidal and atmospheric loadings are not taken into account. 


\section{Results and Discussion}

\subsection{Comparison of the solutions of station position be-} tween the GSJ's array and GEONET

Figure 2 shows the north, east, and vertical components of the Tennoji station (TNNG) for 2.5-year observation. Linear trends of plate tectonic origin are clearly observed in the north and east components. The Jump, found on June 30 1996, is associated with the change from the ITRF93 to ITRF94 coordinates in the fiducial orbit. Except for the jump and linear trends, the repeatabilities of the site coordinates are of the order of a few $\mathrm{mm}$ in horizontal and a few $\mathrm{cm}$ in vertical components. The worse repeatability of the vertical component is mainly due to the annual variation, which will be discussed later in this paper.

Using the solutions, average horizontal station velocities were calculated by linear regression from July 1996 to December 1998. Figure 1 shows the station velocities relative to TSKB. The eastward movement of the stations around the Kansai district with respect to TSKB is clearly seen, which is consistent with previous results, for example, obtained from GEONET (Miyazaki and Hatanaka, 1997).

By comparing the GSJ solution with the result from GEONET, we can evaluate the influence of an antenna type difference on station position estimates. GEONET consists of three types of receiver/antenna systems (Trimble, Ashtech, and Leica), each of which is in principle equipped with different types of antenna mount and radome according to the receiver/antenna type. In order to avoid antenna mixing problems, the stations are divided into several clusters depending on the antenna type, and the data from each cluster is processed separately in the routine analysis. Since the GSJ's array consists of a uniform antenna type which is different from GEONET, we can evaluate the influence of the antenna (PCV) difference on station position estimation. Moreover, we can also evaluate the influence of an antenna mixing problem to some extent. In GEONET, each cluster contains a station at Tsukuba locating near TSKB (hereafter we refer to it as near-TSKB station), which is constrained tightly to determine the coordinates of other stations. The coordinates of the

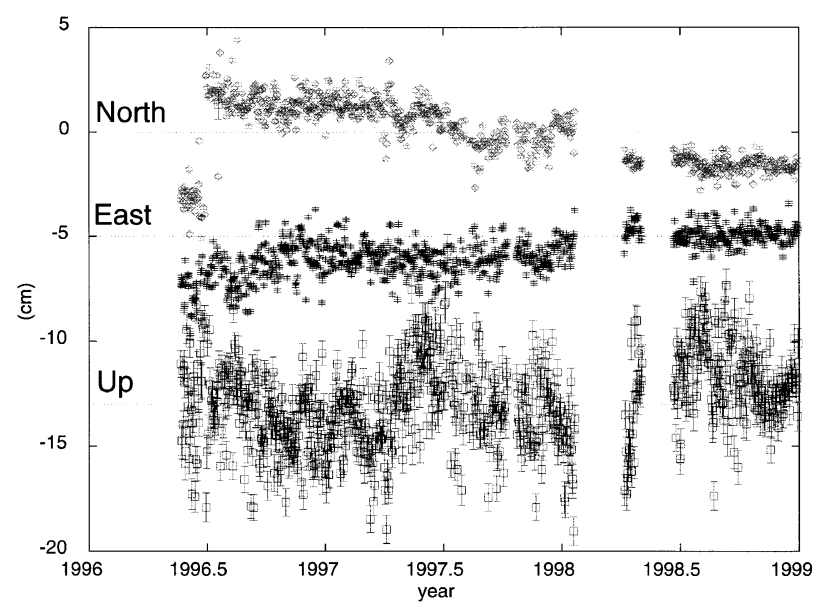

Fig. 2. GPS station position variations at the Tennoji station. From top to bottom, the north, east, vertical components are shown. Bars represent their standard errors.
near-TSKB stations themselves are determined with respect to TSKB separately to realize their ITRF coordinates, which in turn determines the ITRF coordinates of all of the other GEONET stations in each cluster (Miyazaki et al., 1997). However, since TSKB consists of a different type of antenna from those of GEONET, the determination of the station coordinates of the near-TSKB stations is affected through the antenna mixing problem in the analysis between TSKB and the near-TSKB station. On the other hand, none of different types of antenna were used to analyze the GSJ's array. Hence, by comparing the solution of the GSJ's array with that obtained from GEONET, we can evaluate the influence on station position estimation caused by the antenna mixing problem brought by the analysis method described above.

To see this quantitatively, the GEONET stations with Trimble Permanent L1/L2 antennas, within $20 \mathrm{~km}$ from the nearest GSJ's stations, were selected, and the GSJ-GSI difference in the daily solutions were calculated. Figure 3 shows the rms difference to the mean for north, east, and vertical components. In spite of the separation between the GSJ and GSI stations, the rms differences are about $10 \mathrm{~mm}$ for horizontal and 15 to $20 \mathrm{~mm}$ for vertical components, respectively, which indicates that the influences of the antenna difference and/or the antenna mixing are in this order. Therefore, if we discuss only relative variations beyond this level, these influences are not serious.

\subsection{Comparison of the vertical movement with the in situ groundwater-level variation}

Figure 4 shows the time series of the vertical components for the GSJ's stations over the Kansai district. An annual variation, maximum in summer and minimum in winter, can be observed at almost all of the stations. There can also be recognized annual variations in the horizontal component (not shown), however, they are not so predominant compared with the vertical component. In this study, we concentrate our efforts on investigating the vertical component since it is considered to have stronger correlation with groundwaterlevel variation.

Though the phase of the annual variation has good corre-

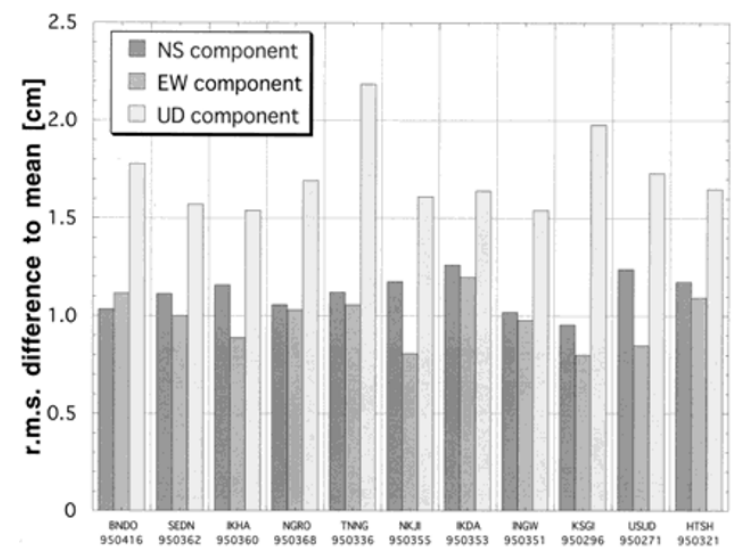

Fig. 3. The rms differences to the means of the daily solutions between the GSJ (labeled by abbreviated station names at the top of columns) and GEONET (labeled by station names as number at the bottom) stations for the north, east, and vertical components for the stations located within 20 km each other. On the GSJ stations' location, see Fig. 1. 




Fig. 4. Variations of the vertical component in the GSJ's GPS stations around the Kansai district.

lation among the stations, the amplitude is different from site to site. For example, the full amplitude of the annual variation at the Tennoji station (TNNG in Fig. 4) is as large as $40 \mathrm{~mm}$. At the Ikeda station (IKDA), only $20 \mathrm{~km}$ apart from the Tennoji station, it is about $25 \mathrm{~mm}$. At the Inagawa station (INGW), apart $10 \mathrm{~km}$ from the Ikeda station, it is only about $10 \mathrm{~mm}$. The amplitude varies considerably although the stations are located closely each other.

It is difficult to attribute the annual variation to errors in modeling the seasonal change of the mapping function since the atmospheric condition is not considered to vary largely within the narrow area. The variation of mapping functions is determined basically by the changes in the ratio of the "thickness" of the atmosphere to the radius of the Earth (Niell, 1996). In modeling the Lanyi mapping function used in this analysis, the thickness of the atmosphere can be mainly described by two atmospheric condition parameters: tropopause height and surface temperature. The former determines the width of the model atmosphere used in the mapping function and the latter determines the atmospheric scale height for the corresponding density (Lanyi, 1984). In fact, the Lanyi mapping function allows us to tune these parameters as well as temperature lapse rate and height of an isothermal layer for adjusting the mapping function according to location and season. In order to investigate the difference of the mapping function among the stations, we compared the variations of the tropopause height and surface temperature. The upper air observations at the nearest 3 meteorological stations surrounding the area (Shionomisaki, $\mathrm{N} 33.45^{\circ}, \mathrm{E} 135.77^{\circ}$; Wajima, N37.38 ${ }^{\circ}, \mathrm{E} 136.90^{\circ}$; Yonago, $\mathrm{N} 35.43^{\circ}, \mathrm{E} 133.35^{\circ}$ ) showed that the seasonal variations of the tropopause height and surface temperature agreed well each other for the period from 1996 to 1997. This fact indicates that the observed large variability of the annual variation can not be explained by the difference of the mapping function over the area. In order to evaluate errors in the mapping function more precisely and quantitatively, it is necessary to calculate tropospheric delay by raytracing an atmospheric profile and see the difference to the corresponding delay calculated from the mapping function. Niell (1996) showed that the rms difference about the mean of the tropospheric delay at $5^{\circ}$ elevation angle between raytracing and the Lanyi mapping function ranged from $20 \mathrm{~mm}$ to $82 \mathrm{~mm}$ over 26 global radiosonde sites for one to two years, which can be considered as a standard error of the mapping function. Since the error in the estimated vertical component is roughly one third of the error in the tropospheric delay at $5^{\circ}$ (Niell, 1996), the variation of the height component caused by the error is roughly up to $27 \mathrm{~mm}$, which is considered to be the upper limit of the height variation induced by the error in the Lanyi mapping function. The value is larger than the observed amplitudes of the annual variations found in the GSJ's array, however, the elevation cutoff is set to be $15^{\circ}$ in this analysis, the variation caused by the error of the mapping function is considered to be smaller. The error in the mapping function may contribute to the annual variation to some extent, however, it is difficult to attribute the annual variation only to the error of the mapping function.

The large variability of the amplitude of the annual variation also makes it difficult to explain the annual variation by ocean tidal and/or atmospheric loading effects because they are not also likely to vary largely within the narrow area. According to the theoretical calculation by Sengoku and Sato (1996), the vertical displacement due to ocean tidal loading for each constituent reaches only the order of $10 \mathrm{~mm}$ over this area. The vertical displacement due to atmospheric loading is the order of a few mm (Sengoku et al., 1998). They are too small to account for some of the observed annual variations. The large variability within the narrow area suggests that the variation is caused by local effects around the observation sites. As one of the local effects, the effect of groundwater is to be discussed here.

Most of the GSJ's groundwater-observation wells, next to the GPS stations, are located on sedimentary basins. They observe "confined" groundwater in relatively deep aquifers, about 200 to 800 meter depths, to detect the variations due to strain changes associated with earthquakes. Confined groundwater is that whose aquifer is sandwiched between impermeable layers. Due to the changes of the external forces such as tide and atmospheric pressure, the aquifer is confined by the stress propagation through the impermeable layer. This induces pressure changes of the groundwater in the aquifer, which result in the change of the groundwater level in the well. Therefore, if the change of the groundwater pressure occurs, for example, by the supply of groundwater due to precipitation or the decrease due to drought, it would force 

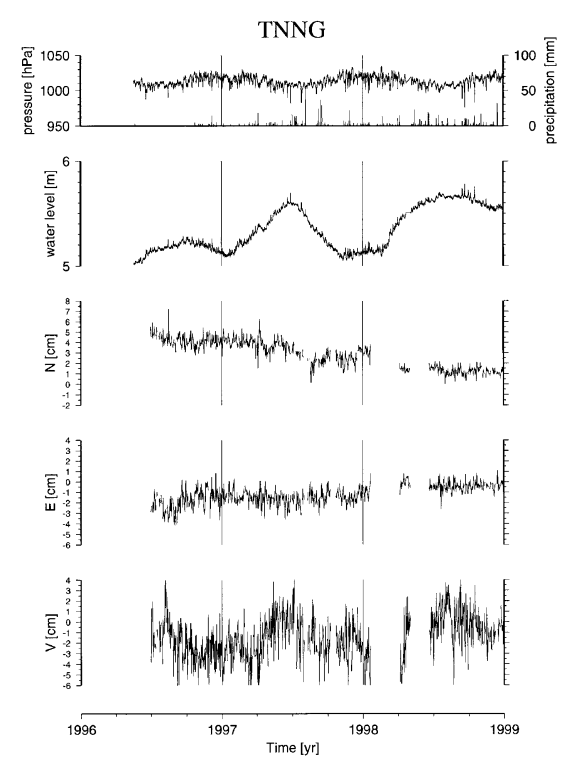

(a)




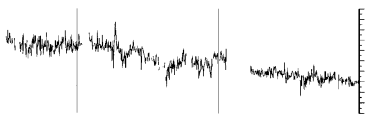

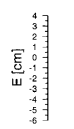
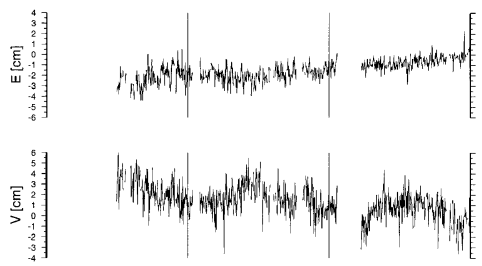

1996

1997
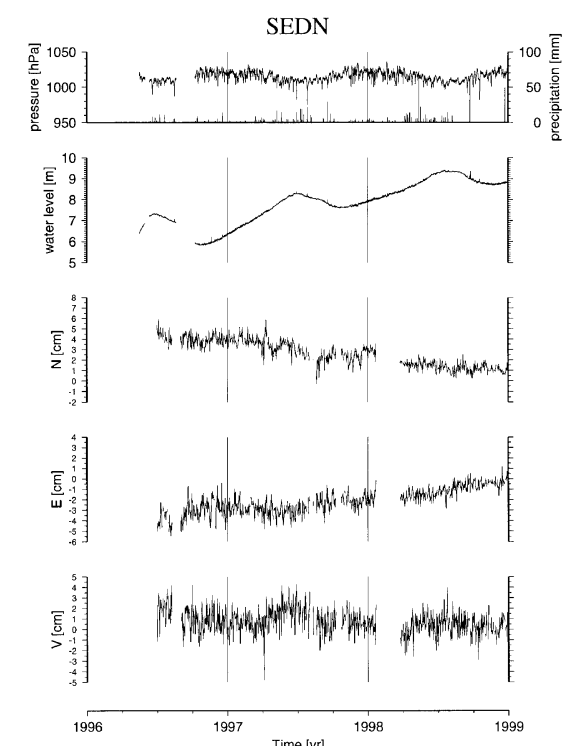

(c)

Fig. 5. From top to bottom, time series of the atmospheric pressure, hourly precipitation, groundwater level, GPS station solutions of the north, east, and vertical components are shown at (a) the Tennoji station (TNNG), (b) the Ikeda station (IKDA), and (c) the Seidan station (SEDN).

the impermeable layer above the aquifer to rise or subside.

One of the examples of the comparison at the Tennoji station, whose annual variation in the vertical component is the largest among the stations (see Fig. 4) is shown in Fig. 5(a). The depth of the screen of the well is about $450 \mathrm{~m}$. There is a predominant annual variation of the groundwater level. There are also fluctuations corresponding to the changes of Earth tides and atmospheric loading, which demonstrate that the aquifer of the groundwater is well confined. The annual variation reaches its maximum in summer and minimum in winter. There is also an annual variation in the atmospheric pressure, but the atmospheric pressure variation with periods longer than a few tens of days does not generally affect confined groundwater because the groundwater leaks through the impermeable layer (Rojstaczer, 1988). Annual changes of groundwater level are widely believed to be due to seasonal changes of precipitation. On the other hand, there is also a dominant annual variation in the GPS vertical station position. Though the daily estimates are rather scattered, there is a good positive correlation with the groundwater annual variation. $50 \mathrm{~cm}$ groundwater-level change roughly corresponds to about $40 \mathrm{~mm}$ change in the vertical component.

Figure 5(b) shows the comparison at the Ikeda station, about $20 \mathrm{~km}$ apart from the Tennoji station. The amplitude of the annual variation in the vertical component is the second largest (see Fig. 4). The depth of the screen of the well is about $550 \mathrm{~m}$, and the stratum of the aquifer belongs to the Osaka group, the same stratum as that of the aquifer at the Tennoji station. The long term steady increase of the groundwater level until the beginning of 1997 is a drift that the groundwater in the aquifer had been permeating into the well until the pressure between the well and the aquifer became equilibrium. There are several spikes in the groundwater level, which correspond to heavy rainfalls. Except these spikes, annual component is the largest but its amplitude is smaller than at Tennoji. The annual variation of $20 \mathrm{~cm}$ in the groundwater level corresponds to about $25 \mathrm{~mm}$ change in the vertical component. The phase of the annual variation is, however, slightly different from the GPS annual variation. Moreover, it is difficult to see vertical variations corresponding to the spikes of the groundwater level.

Figure 5(c) shows the comparison at the Seidan station. The depth of the screen of the well is about $220 \mathrm{~m}$. All of the aquifers shown in these comparisons belong to the Osaka group, which consists of soft sedimentary strata. In this case, the groundwater-level variation is larger than the previous two cases. There is a dominant annual variation with the full amplitude of about $100 \mathrm{~cm}$ with a long-term steady increase. On the other hand, there is also an annual variation in the vertical component, but the amplitude is smaller than the other two cases. Though there seems to be some correlations in the phase of the annual variation between the groundwater and the GPS, there is not a secular variation in the GPS vertical solution similar to the groundwater level. At other stations, the correlations between GPS vertical component and groundwater level are not always good.

To discuss the relation between the groundwater and the GPS more quantitatively for the cases of the Tennoji and Ikeda stations where some correlations are found in the annual component, let us calculate the displacement of surface due to elastic deformation by a groundwater-pressure change. In this case, we consider that the deformation is caused only by the change of the groundwater pressure in the aquifer. The effects of compaction and expansion of the aquifer is not taken into account. Let us assume infinite ground where the aquifer extends at the depth $h$. Increase of groundwater pressure in the aquifer $d p$, which is observed as the change of the groundwater level in the well $d l$, deforms the impermeable layer and causes vertical displacement $d h=h \frac{d p}{k}$ where $k^{-1}$ is the compressibility of the stratum between the 
aquifer and the surface. Since the relation between $d l$ and $d p$ can be described as $d l=\frac{d p}{\rho g}$ where $\rho$ is the density of the groundwater and $g$ is the gravity acceleration, we can obtain $d h=h \frac{d l \cdot \rho g}{k}$ if the value $k$ is known. $k$ can be obtained from the direct measurement of the drilling core at the observation well. For the Tennoji station, which is located exactly on a fault zone, the observed amplitude of the annual variation of the groundwater level is about $500 \mathrm{~mm}$. Unfortunately, there are no measurements of $k$ between the surface and the aquifer, the measurement of $k$ at the aquifer $\left(k=3.12 \times 10^{6}\right.$ $\left.\left(\mathrm{N} / \mathrm{mm}^{2}\right)\right)$ will be used instead. Using these values, the calculated displacement becomes about $7 \mathrm{~mm}$. However, the amplitude of the vertical annual variation in GPS is about $50 \mathrm{~mm}$. For the Ikeda station, by substituting $d l=200 \mathrm{~mm}$, $k=2.74 \times 10^{8}\left(\mathrm{~N} / \mathrm{mm}^{2}\right)$, the change of the vertical displacement becomes $0.05 \mathrm{~mm}$, which is too small in comparison with the GPS derived amplitude of about $25 \mathrm{~mm}$.

These results indicate that at least for the stations examined here, groundwater is not likely to induce vertical displacements. The annual variation found in the GPS vertical components should be attributed to other causes. However, it should be noted that in this study, groundwater data from a single aquifer was used. The correlation with groundwater level from other aquifers at various depths, especially groundwater at more shallow depth, say, $100 \mathrm{~m}$, should be investigated because groundwater in shallow aquifers varies larger than that in the deeper aquifers in general. In addition, estimation using more sophisticated and realistic models, for example, including the effects of compaction and expansion of an aquifer due to supply and withdrawal of groundwater, which were calculated by Matsumoto (1996) and Koide et al. (1989) using the measurement of compaction and expansion coefficients obtained from drilling core, is necessary to discuss the groundwater effect more precisely and quantitatively.

\section{Conclusion}

With the observation for 2.5 years by the GSJ's regional CGPS array, we conclude as follows. By comparing the station position solution with that obtained from GEONET, the agreement showed about $10 \mathrm{~mm}$ in horizontal and 15 to 20 $\mathrm{mm}$ in vertical components. The GPS stations around the Kansai district showed a common annual variation in the vertical component, whose amplitude was different from site to site. The annual variations were compared with the in situ groundwater levels, but the correlation between them was not good enough.

Acknowledgments. We gratefully acknowledge H. Ito, M. Takahashi, Y. Kuwahara, T. Sato, and T. Satoh for their efforts in constructing and maintaining the GSJ's array. We thank K. Hurst and F. Webb for their cooperation in establishing the routine analysis system of the GSJ's GPS array using GIPSY. We thank GSI for providing us the result from the routine analysis of GEONET. We thank the two referees (K. Heki and M. Murakami) for their comments and suggestions in improving the manuscript.

\section{References}

Elósegui, P., J. L. Davis, R. T. K. Jaldehag, J. M. Johansson, A. E. Niell, and I. I. Shapiro, Geodesy using the Global Positioning System: The effects of signal scattering on estimates of site position, J. Geophys. Res., 100, 9921-9934, 1995.

Geographical Survey Institute, Crustal deformations in the Boso peninsula, in Report of the Coordinating Committee for Earthquake Prediction, edited by Geographical Survey Institute, 57, pp. 223-236, Geographical Survey Institute, Tsukuba, Ibaraki, 1997 (in Japanese).

Heki, K., S. Miyazaki, and H. Tsuji, Silent fault slip following an interplate thrust earthquake at the Japan Trench, Nature, 386, 595-598, 1997.

Jaldehag, R. T. K., J. M. Johansson, B. O. Ronnang, P. Elósegui, J. L. Davis., I. I. Shapiro, and A. E. Niell, Geodesy using the Swedish permanent GPS network: Effects of signal scattering on estimates of relative site positions, J. Geophys. Res., 101, 17841-17860, 1996.

Koide, H., M. Takahashi, T. Kanema, and Z. Xue, Compaction and expansion of sedimentary rocks due to the pore water pressure change and their effect on subsidence and re-upheaval, J. Japan Society of Engineering Geology, 30, 15-25, 1989 (in Japanese).

Koizumi, N., E. Tsukuda, M. Takahashi, T. Sato, N. Matsumoto, H. Ito, Y. Kuwahara, A. Cho, and T. Satoh, Groundwater level observation of Geological Survey of Japan in and around the Kinki district, Japan for earthquake prediction research, J. Balneological Soc. Japan, 49, 18-33, 1999 (in Japanese).

Lanyi, G., Tropospheric delay effects in radio interferometry, in Tracking and Data Acquisition Prog. Rept. 42-78, vol. April-June 1984, pp. 152159, Jet Propulsion Lab., Pasadena, Calif., 1984.

Matsumoto, N., Variation of groundwater level in the Tokai region, Chikyu Monthly, 14, 33-41, 1996 (in Japanese).

Matsumoto, N., Comparison of ground water level and heights relative to Kakegawa in Hamaoka, Shizuoka, in Report of the Coordinating Committee for Earthquake Prediction, edited by Geographical Survey Institute, 59, pp. 357-363, Geographical Survey Institute, Tsukuba, Ibaraki, 1998 (in Japanese).

Meertens, C., C. Alber, J. Braun, C. Rocken, B. Stephens, R. Ware, M. Exner, and P. Kolesnikoff, Field and anechoic chamber tests of GPS antennas, in Proc. International GPS Service for Geodynamics Analysis Center Workshop, 1996, edited by R. E. Neilan, P. A. Van Scoy, and J. F. Zumberge, pp. 107-118, Jet Propulsion Lab. Pasadena, Calif., 1997.

Miyazaki, S. and Y. Hatanaka, Crustal deformation observed by GSI's new GPS array, EOS Trans. Am. Geophys. Union, 78(17), S104, 1997.

Miyazaki, S., T. Saito, M. Sasaki, Y. Hatanaka, and Y. Iimura, Expansion of GSI's nationwide GPS array, Bull. of the Geographical Survey Institute, 43, 23-34, 1997.

Niell, A. E., Global mapping functions for the atmosphere delay at radio wavelengths, J. Geophys. Res., 101, 3227-3246, 1996.

Roeloffs, E. A., Hydrologic precursors to earthquakes: a review, Pure Appl. Geophys., 126, 177-206, 1988.

Rojstaczer, S. A., Determination of fluid flow properties from the response of water levels in wells to atmospheric loading, Water Resource Res., 24, 1927-1938, 1988.

Sagiya, T., Interplate coupling in the Tokai district, central Japan, deduced from continuous GPS data, Geophys. Res. Lett., 26, 2315-2318, 1999.

Sengoku, A. and T. Sato, Ocean loading site displacement around Japan, in Report of Hydrographic Researches, 32, pp. 129-135, Hydrographic Department of Japan, Tsukiji, Tokyo, 1996 (in Japanese).

Sengoku, A., T. Sato, Y. Hatanaka, S. Miyazaki, and S. Shimada, Deformation due to atmospheric loading and GPS, in Proc. of GPS Joint Symposium, Nov. 30-Dec. 2, 1998, p. 18, Kyoto Univ., Uji, Kyoto, 1998 (in Japanese).

Tada, T., Is the western margin of Fossa-magna a plate boundary? (2), Programme Abstr. Annu. Meet. Seismol. Soc. Jpn., 2, B33, 1996 (in Japanese).

Tsukuda, E., M. Takahashi, T. Sato, N. Matsumoto, and H. Ito, Groundwater observation network system for earthquake prediction research of the Geological Survey of Japan - New observation wells in the Kinki district - , Chishitsu News, 505, 11-15, 1996 (in Japanese).

Webb, F. H. and J. F. Zumberge, An introduction to the GIPSY/OASIS-II, JPL Publ., D-11088, Jet Propulsion Lab. Pasadena, Calif., 1993.

Zumberge, J. F., M. B. Heflin, D. C. Jefferson, M. M. Watkins, and F. H. Webb, Jet Propulsion Laboratory IGS Analysis Center 1994 Annual Report, in International GPS Service for Geodynamics, 1994 Annu. Rep., edited by J. F. Zumberge, R. Liu, and R. E. Neilan, pp. 185-196, Jet Propulsion Lab., Pasadena, Calif., 1995.

R. Ohtani (e-mail: ryu@gsj.go.jp), N. Koizumi (e-mail: koizumi@gsj go.jp), N. Matsumoto (e-mail: norio@gsj.go.jp), and E. Tsukuda (e-mail: tsukuda@gsj.go.jp) 